\title{
Article \\ Comparison of Clinical Parameters in Dental Implant Therapy between Implant Site Development Using Porcine- and Bovine-Derived Xenografts
}

\author{
Li-Ching Chang ${ }^{1,2}$
}

check for updates

Citation: Chang, L.-C. Comparison of Clinical Parameters in Dental Implant Therapy between Implant Site Development Using Porcine- and Bovine-Derived Xenografts. Technologies 2021, 9, 72. https:// doi.org/10.3390/technologies 9040072

Academic Editor: Fabrizio Stasolla

Received: 10 September 2021 Accepted: 30 September 2021 Published: 1 October 2021

Publisher's Note: MDPI stays neutral with regard to jurisdictional claims in published maps and institutional affiliations.

Copyright: (C) 2021 by the author. Licensee MDPI, Basel, Switzerland. This article is an open access article distributed under the terms and conditions of the Creative Commons Attribution (CC BY) license (https:// creativecommons.org/licenses/by/ $4.0 /)$.
1 Department of Dentistry, Chang Gung Memorial Hospital, Chiayi 61363, Taiwan; liching@ms39.hinet.net 2 Institute of Nursing and Department of Nursing, Chang Gung University of Science and Technology, Chiayi 61363, Taiwan

\begin{abstract}
Purpose: The aim of this study is to compare the effects of two xenografts, i.e., porcine- and bovine-derived xenografts, on dental implant therapy after implant site development. Materials and Methods: This retrospective study involved adults who underwent dental implantation between January 2012 and December 2020. Various patient and implant-site characteristics were collected from the patient records. The implant-surgery clinical parameters of the porcine- and bovine-derived xenografts used for implant site development were analyzed and compared. Results: A total of 116 subjects with 168 dental implants were included in this study. There was less soft bone in the porcine bone group of the maxilla. However, there was less soft bone and a greater percentage of "primary stability $\geq 35 \mathrm{~N}$ " in the bovine bone group of the mandible. However, no significant differences in regrafting rate, post-operative infection rate, or implant survival rate were found between the bovine and porcine bone groups. Conclusion: The effects of implant site development using bovine- and porcine-origin xenografts are comparable in terms of the implant-therapy clinical parameters, including the regrafting rate and implant survival rate. Thus, the choice of xenografts could be made according to the patient's religious requirements. However, the reported results should be used with caution, considering the limitations of this retrospective study.
\end{abstract}

Keywords: xenograft; bovine bone; porcine bone; dental implant; primary stability; implant site development

\section{Introduction}

Bone regeneration is a common dental procedure, especially for the development of dental implant sites. Many graft materials are clinically applied, including autografts, allografts, xenografts, and alloplasts [1]. Xenografts resorbed slower than calcium sulphate, beta-tricalcium phosphate, or allografts, thus, xenografts preserved more bone volume when compared with calcium sulphate, beta-tricalcium phosphate, or allografts [1]. Hydroxyapatite (HA) results in voids between the graft and bone tissue due to retention at the surgical site. Thus, the result of ridge augmentation using HA is not consistently favorable [2]. Porous titanium granules and oxidized white porous titanium granules have better mechanical properties than deproteinized bovine bone mineral (DBBM). However, early implant stability, osseointegration, and bone healing were not improved with the application of these mechanically stronger metal grafts [3]. Good bone quality could obtain a high primary stability value and increase the dental implant success rate. However, it is possible to enhance primary stability by specific techniques (e.g., osseodensification drill) in poor bone quality for implant success rate [4].

Xenografts can be of bovine, porcine, or equine origin [5]. To avoid immunologic problems and the risk of transmission, complete protein removal is required. After protein destruction, the carbonated hydroxyapatite is similar to human bone [5]. Bovine-derived bone grafts were the first widely used xenografts in dentistry [6]. These grafts exhibit 
not only high porosity, but also nanoscale pores, which are also found in human bone [6]. However, porcine-derived bone grafts have recently been developed and made commercially available for bone regeneration [6-9]. Most of the key physiochemical characteristics of porcine- and bovine-derived bone grafts are similar, but significant differences were found in terms of the porosity, crystallinity, pore distribution, and particle size of different xenografts $[6,10]$. Additionally, porcine bone is closer to human trabecular bone than bovine bone in terms of the stiffness, $\mathrm{Ca} / \mathrm{P}$ ratio, and mineral content $[10,11]$. However, both biomaterials are biocompatible and osteoconductive, which means they can be used as bone substitutes without interfering with normal reparative bone processes [8].

When applied to rat calvarial defects, porcine- and bovine-derived xenografts have had similar effects in terms of new bone volume and area [12]. In a canine model, however, significantly more new bone formation and better bone bridging have been observed for porcine than bovine bone [13]. In clinical sinus augmentation, porcine bone may produce similar bone formation and volumetric stability to bovine bone [7]. Furthermore, when applied to sinus augmentation, ingrowth of newly formed bone and vessels in the pores of partially resorbed particles of these grafts has been observed [9]. Bovine and porcine bone can comparably augment damaged extraction sockets in the vertical and horizontal dimensions [14]. However, more pronounced vertical ridge alteration has been observed for porcine bone plus cross-linked collagen membrane compared to bovine bone plus non-cross-linked collagen membrane [15]. Finally, comparable proportions of residual biomaterial, newly formed bone, and nonmineralized tissue have been observed for the application of bovine and porcine bone to bone regeneration $[7,16]$, and similar histologic bone formation has also been found for socket grafting using bovine or porcine bone covered by collagen membranes in periodontally damaged extraction sockets [16].

To the best of our knowledge, a small number of studies have focused on comparing these two different-origin xenografts in the context of implant site development $[7,14,17]$. Our hypothesis is that no significant differences exist between the clinical parameters of dental implant therapy for application of bovine- and porcine-derived xenografts to implant site development. The clinical parameters included bone density, primary stability, and implant survival rate. Therefore, the aim of this study is to compare the effects of bovineand porcine-derived xenografts on dental implant therapy after implant site development.

\section{Materials and Methods}

\subsection{Study Subjects}

This retrospective study involved adults who underwent dental implantation with the author, Dr. Li-Ching Chang in the Dental Department of Chang-Gung Memorial Hospital, Chiayi Branch, between January 2012 and December 2020. The inclusion criteria were as follows: (1) Extraction was performed in our department, and (2) ridge preservation/augmentation for dental implant site development was performed by Dr. Chang. The exclusion criteria were as follows: (1) The dental implant site healed naturally (without bone grafting) before implant placement, (2) another bone graft (not a xenograft) was used in the ridge preservation/augmentation procedure, (3) the period between orthodontic treatment and dental implant placement was less than two years, and (4) prosthetic work was not completed before this study.

\subsection{Procedures Performed}

Ridge preservation/augmentation was performed before the dental implant placement. The xenografts used were bovine- (B group; Bio-Oss, Geistlich Biomaterials, Princeton, NJ, USA) and porcine-derived (P group; Miner-Oss $\mathrm{XP}^{\circledR}{ }^{\circledR}$, BioHorizons, Birmingham, $\mathrm{AL}, \mathrm{USA}$ ). In all cases of flapless ridge preservation, a collagen plug (Teruplug, Olympus Terumo Biomaterials, Tokyo, Japan) or a porcine collagen membrane (Sunmax collagen dental membrane, Sunmaxbiotech Co., Ltd., Tainan, Taiwan) was used as the coronal seal for the B and P groups, respectively (Figures 1 and 2). After 3-5 months, $3 i$ system implants (3i Osseotite or $3 \mathrm{i}$ Tapered Certain, Biomet, Warsaw, IN, USA) were placed in the developed implant sites. All implants 
were placed after flap elevation under local dental anesthesia, and the wound was closed with suture. Postoperative antibiotics and analgesics were prescribed for 3-7 days. The suture was removed within 2-4 weeks, and follow-up was conducted once every 1-2 months before prosthetic work completion.

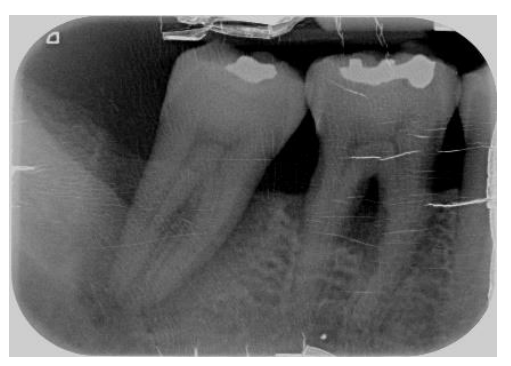

(a)

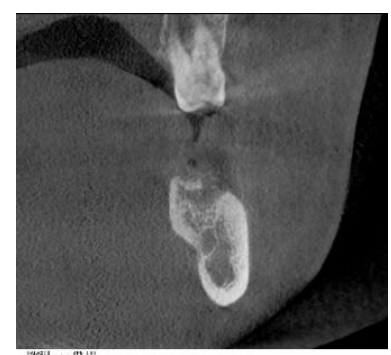

(c)

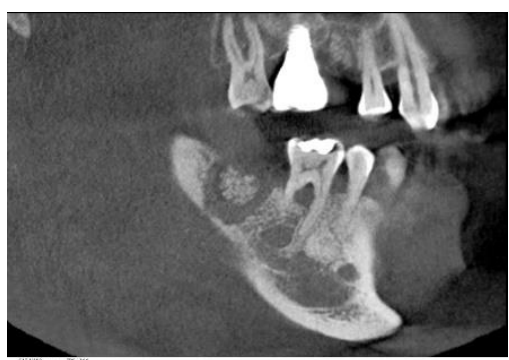

(b)

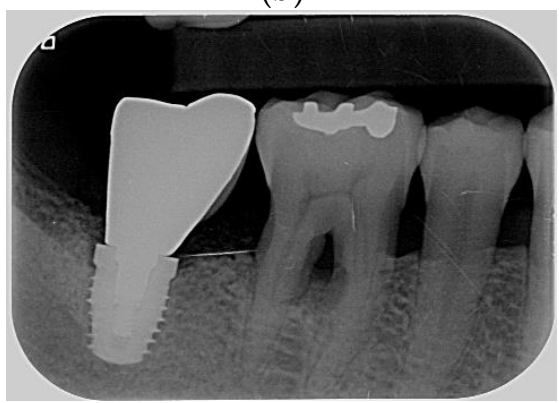

(d)

Figure 1. Implant site development of 62-year-old male patient using bovine bone and porcine collagen plug: (a) periodontitis-induced severe bone destruction on right-mandible second molar; (b) result three months after flapless ridge preservation shown in cone beam computed tomography (CBCT; sagittal view); (c) CBCT (frontal views); and (d) follow-up after prosthetic completion.

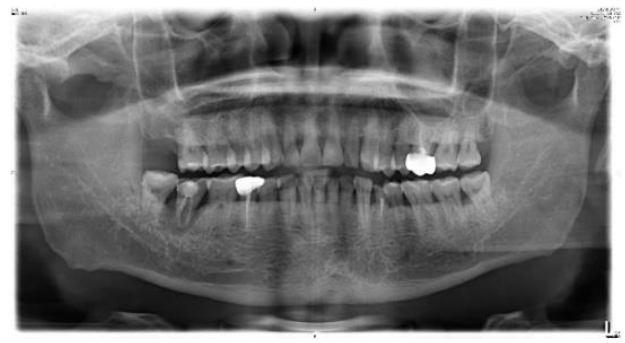

(a)

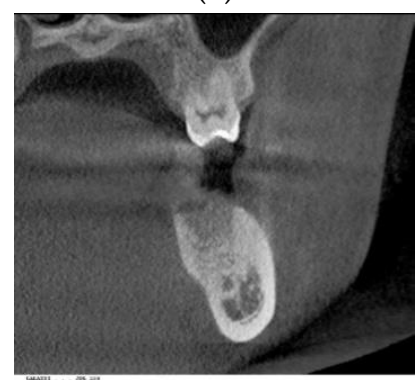

(c)

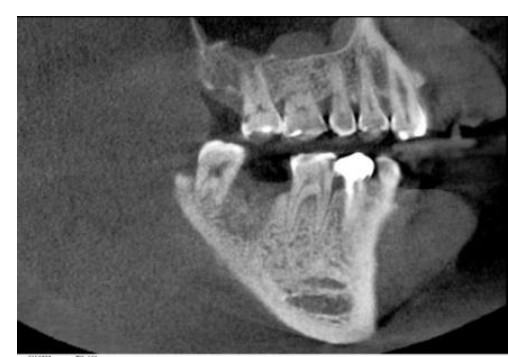

(b)

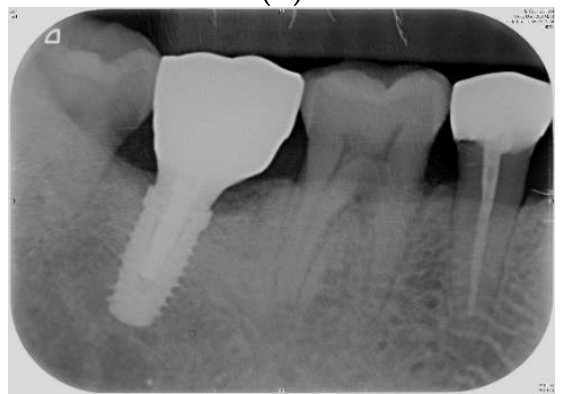

(d)

Figure 2. Implant site development of 49-year-old male patient using porcine bone and porcine collagen membrane: (a) severe bone loss on right-mandible second molar due to root fracture; (b) result 3 months after ridge augmentation (five months post-extraction) shown in cone beam computed tomography (CBCT; sagittal view); (c) CBCT (frontal views); and (d) follow-up after prosthetic completion. 


\subsection{Data Collection}

Demographic and clinical characteristics were retrieved from patient records, including details of systemic conditions, sex, age, and smoking status. The patient systemic conditions were classified into four groups: "healthy," "diabetes mellitus (DM)," "osteoporosis," and "other disease" (excluding DM and osteoporosis). The patient smoking status results at Stage-I implant surgery were recorded as "current smoker," "former smoker" (smoking cessation before implant placement), or "nonsmoker" (no history of smoking).

The implant sites were divided into maxillary and mandibular areas. Implant site development included ridge preservation (RP) combined with tooth extraction or ridge augmentation due to ridge resorption after extraction (RA). The extraction etiology was classified as periodontal or non-periodontal (e.g., due to a residual root, caries, or root fracture) disease. During implant surgery, the bone density was classified as "soft bone (D4)" or "non-soft bone (D1, D2, and D3)" according to the texture of the implant preparation site [18]. The peak insertion torque $(\mathrm{N} / \mathrm{cm})$ of the implant placement was recorded as an implant-stability reference point. Additional procedures were combined with the implant placement, i.e., sinus lifting (SL) and bone regrafting (BG). Clinical signs and symptoms of infection appearing during the osseointegration phase, such as a sinus tract or abscess, were defined as "post-operative infection." The implant survival rate was classified as "survival" or "early implant failure" before loading.

Four different time periods were considered: T1, the time between tooth extraction and bone grafting; $\mathrm{T} 2$, the time between bone grafting and implant Stage I surgery; T3, the time between implant Stage I and Stage II surgery; and T4, the time between implant Stage II surgery and prosthetic completion (Figure 3).

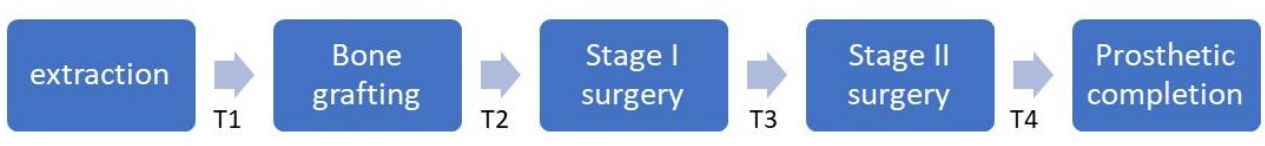

Figure 3. Definitions of different time periods. T1: Time between tooth extraction and bone grafting, T2: Time between bone grafting and implant Stage I surgery, T3: Time between implant Stage I surgery and Stage II surgery. T4: time between implant Stage II surgery and prosthetic completion. The time between extraction and prosthetic completion was TT, i.e., total treatment $=\mathrm{T} 1+\mathrm{T} 2+\mathrm{T} 3+\mathrm{T} 4$, and the time between bone grafting and prosthetic completion was $\mathrm{TI}$, i.e., implantation time $=\mathrm{T} 2+\mathrm{T} 3+\mathrm{T} 4$.

The study was conducted in accordance with the Helsinki Declaration of 1975, as revised in 2013. The protocol was approved by the Institutional Board of Chang-Gung Memorial Hospital (No. 202100702B0).

\subsection{Statistical Analysis}

The subject age was expressed as the mean \pm standard deviation (SD). For the age parameter, the differences between the two groups receiving the different RA materials, i.e., the $\mathrm{B}$ and $\mathrm{P}$ groups, were tested via an independent two-sample $t$-test. As skew distributions were involved, the other continuous data elements related to the treatment times $(\mathrm{T} 1, \mathrm{~T} 2, \mathrm{~T} 3, \mathrm{~T} 4, \mathrm{~T} 2+\mathrm{T} 3, \mathrm{~T} 2+\mathrm{T} 3+\mathrm{T} 4$, and $\mathrm{T} 1+\mathrm{T} 2+\mathrm{T} 3+\mathrm{T} 4)$ were presented as medians and interquartile ranges (IQR, the range between the 25th and 75th percentiles). The differences between the B and P groups were tested using the Mann-Whitney test. Categorical variables were presented as counts and percentages, and their associations with the RA materials were assessed using Fisher's exact test.

Univariable and multivariable logistic regression models were used to determine the independent influence factors of the primary stability $(>35 \mathrm{~N})$. In the univariable logistic regression models, variables with $p$-values less than 0.2 were entered stepwise into the multivariable analyses to obtain a final optimized model. The above statistical analyses were performed using IBM SPSS Statistics 25.0 software (IBM Corporation, Armonk, NY, USA). A two-tailed $p$ value of $<0.05$ indicated statistical significance. 


\section{Results}

\subsection{Baseline Conditions vs. Xenograft Materials}

During the study period, 116 subjects with 168 dental implants (104 maxillary and 64 mandibular sites) were enrolled. The associations of the implant-site baseline conditions with the $\mathrm{B}$ and $\mathrm{P}$ groups are presented in Tables 1 and 2, for the maxillary and mandibular sites, respectively.

Table 1. Basic characteristics of maxilla implant sites for bovine and porcine bone groups.

\begin{tabular}{|c|c|c|c|c|}
\hline & & $\begin{array}{c}\text { Bovine Bone, } \\
\text { BioOss }(n=65)\end{array}$ & $\begin{array}{c}\text { Porcine Bone, } \\
\text { MinerOss }(n=39)\end{array}$ & $p$-Value \\
\hline \multicolumn{2}{|c|}{ Age (Year) } & $50.6(11.7)$ & $55.8(11.1)$ & $0.029 *$ \\
\hline \multirow{3}{*}{ Sex } & Female & $23(35.4 \%)$ & $17(43.6 \%)$ & 0.414 \\
\hline & Male & $42(64.6 \%)$ & $22(56.4 \%)$ & \\
\hline & Healthy & $30(46.2 \%)$ & $16(41.0 \%)$ & 0.770 \\
\hline \multirow{3}{*}{ Systemic disease } & Diabetes mellitus & $4(6.2 \%)$ & $1(2.6 \%)$ & \\
\hline & Osteoporosis & $2(3.1 \%)$ & $2(5.1 \%)$ & \\
\hline & Other disease & $29(44.6 \%)$ & $20(51.3 \%)$ & \\
\hline \multirow{4}{*}{ Smoking status } & No & 49 (75.4\%) & $33(84.6 \%)$ & 0.400 \\
\hline & Former & $15(23.1 \%)$ & $5(12.8 \%)$ & \\
\hline & Current & $1(1.5 \%)$ & $1(2.6 \%)$ & \\
\hline & Anterior & $8(12.3 \%)$ & $7(17.9 \%)$ & 0.727 \\
\hline \multirow[t]{2}{*}{ Tooth site } & Premolar & $23(35.4 \%)$ & $12(30.8 \%)$ & \\
\hline & Molar & $34(52.3 \%)$ & $20(51.3 \%)$ & \\
\hline \multirow{3}{*}{ Extraction etiology } & Non-periodontitis & $25(38.5 \%)$ & $24(61.5 \%)$ & 0.027 * \\
\hline & Periodontitis & $40(61.5 \%)$ & $15(38.5 \%)$ & \\
\hline & None & $6(9.2 \%)$ & $2(5.1 \%)$ & $<0.001 *$ \\
\hline \multirow{2}{*}{ Coronal seal } & Membrane & $19(29.2 \%)$ & $35(89.7 \%)$ & \\
\hline & Collagen plug & $40(61.5 \%)$ & $2(5.1 \%)$ & \\
\hline Time of ridge & $\mathrm{RP}$ & $41(63.1 \%)$ & $17(43.6 \%)$ & 0.067 \\
\hline recontouring & RA & $24(36.9 \%)$ & $22(56.4 \%)$ & \\
\hline
\end{tabular}

*A $p$-value $<0.05$ indicates a significant difference between the bovine and porcine bone groups. Data are presented as counts and percentages, except for age, and are expressed as the mean \pm SD. RP: ridge preservation, RA: ridge augmentation.

Table 2. Basic characteristics of mandible implant sites for bovine and porcine bone groups.

\begin{tabular}{|c|c|c|c|c|}
\hline & & $\begin{array}{c}\text { Bovine Bone, } \\
\text { BioOss }(n=45)\end{array}$ & $\begin{array}{c}\text { Porcine Bone, } \\
\text { MinerOss }(n=19)\end{array}$ & $p$-Value \\
\hline \multicolumn{2}{|c|}{ Age (Year) } & $49.2(9.0)$ & $54.0(9.6)$ & 0.061 \\
\hline \multirow{3}{*}{ Sex } & Female & $19(42.2 \%)$ & $7(36.8 \%)$ & \\
\hline & Male & $26(57.8 \%)$ & $12(63.2 \%)$ & 0.784 \\
\hline & Healthy & $19(42.2 \%)$ & $12(63.2 \%)$ & \\
\hline \multirow{4}{*}{ Systemic disease } & Diabetes mellitus & $1(2.2 \%)$ & $1(5.3 \%)$ & \\
\hline & Osteoporosis & $2(4.4 \%)$ & $0(0.0 \%)$ & 0.284 \\
\hline & Other disease & $23(51.1 \%)$ & $6(31.6 \%)$ & \\
\hline & No & $34(75.6 \%)$ & $13(68.4 \%)$ & \\
\hline \multirow[t]{3}{*}{ Smoking status } & Former & $10(22.2 \%)$ & $5(26.3 \%)$ & 0.658 \\
\hline & Current & $1(2.2 \%)$ & $1(5.3 \%)$ & \\
\hline & Anterior & $2(4.4 \%)$ & $1(5.3 \%)$ & \\
\hline \multirow[t]{2}{*}{ Tooth site } & Premolar & $12(26.7 \%)$ & $5(26.3 \%)$ & 1.000 \\
\hline & Molar & $31(68.9 \%)$ & $13(68.4 \%)$ & \\
\hline \multirow{3}{*}{ Extraction etiology } & Non-periodontitis & $26(57.8 \%)$ & $12(63.2 \%)$ & \\
\hline & Periodontitis & $19(42.2 \%)$ & $7(36.8 \%)$ & 0.784 \\
\hline & None & $5(11.1 \%)$ & $2(10.5 \%)$ & \\
\hline \multirow{2}{*}{ Coronal Seal } & Membrane & $8(17.8 \%)$ & $17(89.5 \%)$ & $<0.001$ * \\
\hline & Collagen plug & $32(71.1 \%)$ & $0(0.0 \%)$ & \\
\hline \multirow{2}{*}{$\begin{array}{l}\text { Time of ridge } \\
\text { recontouring }\end{array}$} & $\mathrm{RP}$ & $31(68.9 \%)$ & $7(36.8 \%)$ & \\
\hline & RA & $14(31.1 \%)$ & $12(63.2 \%)$ & $0.026^{*}$ \\
\hline
\end{tabular}

${ }^{{ }^{7} \mathrm{~A} p \text {-value }<0.05 \text { indicates a significant difference between the bovine and porcine bone groups. Data are }}$ presented as counts and percentages, except for age, and are expressed as the mean \pm SD. RP: ridge preservation, RA: ridge augmentation.

\subsubsection{Maxillary Sites}

For the maxillary site implants, significant associations in age, extraction etiology, and coronal seal versus the $\mathrm{B}$ and $\mathrm{P}$ groups were observed. That is, the B-group patients were significantly younger than those of the P group (mean age: 50.6 vs. 55.8 years, $p=0.029$ ). 
Compared to the $\mathrm{P}$ group, there were significantly more implant sites with periodontitis in the B group ( $61.5 \%$ vs. $38.5 \%, p=0.027)$. Furthermore, the B group had significantly fewer implant sites with membranes as the coronal seal ( $29.2 \%$ vs. $89.7 \%)$ and significantly more implant sites with a collagen plug as the coronal seal $(61.5 \%$ vs. $5.1 \%, p<0.001)$. No significant associations were observed for the other baseline conditions (sex, systemic disease, smoking status, tooth site, RP, or RA) versus the B and P groups (Table 1).

\subsubsection{Mandible Sites}

For the mandible site implants, no significant associations were observed for the coronal seal and RP versus the $\mathrm{B}$ and $\mathrm{P}$ groups. Compared to the $\mathrm{P}$ group, the $\mathrm{B}$ group had fewer implant sites with membrane $(17.8 \%$ vs. $89.5 \%)$ and more implant sites with collagen plugs $(71.1 \%$ vs. $0 \%, p<0.001)$, and more RP was found for the B group $(68.9 \%$ vs. $36.8 \%$, $p=0.026)$. No significant associations were observed for the other baseline conditions (age, sex, systemic disease, smoking status, tooth site, and extraction etiology) vs. the B and $\mathrm{P}$ groups (Table 2).

\subsection{Implant Site Development vs. Xenograft Materials}

The associations between the implant site development and the $\mathrm{B}$ and $\mathrm{P}$ groups are presented in Tables 3 and 4 for the maxillary and mandibular sites, respectively.

Table 3. Implant site development for bovine and porcine bone groups at maxilla implant sites.

\begin{tabular}{|c|c|c|c|c|}
\hline & & $\begin{array}{l}\text { Bovine Bone, } \\
\text { BioOss }(n=65)\end{array}$ & $\begin{array}{c}\text { Porcine Bone, } \\
\text { MinerOss }(n=39)\end{array}$ & $p$-Value \\
\hline \multirow{3}{*}{ Primary stability $\ddagger$} & $<20 \mathrm{~N}$ & $13(20.6 \%)$ & $14(35.9 \%)$ & \multirow{3}{*}{0.231} \\
\hline & $20-35 \mathrm{~N}$ & $22(34.9 \%)$ & $10(25.6 \%)$ & \\
\hline & $\geq 35 \mathrm{~N}$ & $28(44.4 \%)$ & $15(38.5 \%)$ & \\
\hline \multirow[b]{2}{*}{ Bone density } & $\overline{\mathrm{D}} 1-\mathrm{D} 3$ & $9(13.8 \%)$ & $14(35.9 \%)$ & \multirow[b]{2}{*}{0.014 * } \\
\hline & D4 & $56(86.2 \%)$ & $25(64.1 \%)$ & \\
\hline \multirow[b]{2}{*}{ BG } & Yes & $36(55.4 \%)$ & $23(59.0 \%)$ & \multirow[b]{2}{*}{0.838} \\
\hline & No & $29(44.6 \%)$ & $16(41.0 \%)$ & \\
\hline \multirow[b]{2}{*}{ SL } & Yes & $35(53.8 \%)$ & $18(46.2 \%)$ & \multirow[b]{2}{*}{0.544} \\
\hline & No & $30(46.2 \%)$ & $21(53.8 \%)$ & \\
\hline \multirow{2}{*}{ Post-operative infection } & Yes & $4(6.2 \%)$ & $6(15.4 \%)$ & \multirow[b]{2}{*}{0.170} \\
\hline & No & $61(93.8 \%)$ & $33(84.6 \%)$ & \\
\hline \multirow{2}{*}{ Implant survival } & Early failure & $3(4.6 \%)$ & $0(0.0 \%)$ & \multirow[b]{2}{*}{0.290} \\
\hline & Survival & $62(95.4 \%)$ & $39(100.0 \%)$ & \\
\hline \multirow{2}{*}{$\begin{array}{l}\text { Extraction-bone grafting } \\
\text { (T1, day) }\end{array}$} & $\mathrm{RP}$ & 0 & 0 & NA \\
\hline & RA & $84.0(36.0,158.5)$ & $40.5(35.0,50.0)$ & 0.030 * \\
\hline \multicolumn{2}{|c|}{ 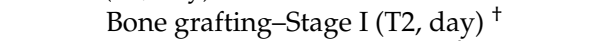 } & $110.0(95.0,135.0)$ & $123.0(107.0,141.0)$ & 0.090 \\
\hline \multicolumn{2}{|c|}{ Stage I-Stage II (T3, day) ${ }^{+}$} & $261.0(231.0,343.0)$ & $238.0(208.0,288.0)$ & 0.054 \\
\hline \multicolumn{2}{|c|}{ Stage II-prosthetic completion (T4, day) ${ }^{\dagger}$} & $99.0(67.0,127.0)$ & $103.0(68.0,112.0)$ & 0.587 \\
\hline \multicolumn{2}{|c|}{ Bone grafting-Stage II (T2 + T3, day) ${ }^{\dagger}$} & $393.0(346.0,463.0)$ & $373.0(336.0,419.0)$ & 0.302 \\
\hline \multicolumn{2}{|c|}{ Bone grafting-completion $\left(\mathrm{T} 2+\mathrm{T} 3+\mathrm{T} 4\right.$, day) ${ }^{\dagger}$} & $477.0(431.0,584.0)$ & $469.0(420.0,530.0)$ & 0.283 \\
\hline Extraction-completion & $\mathrm{RP}$ & $481.0(442.0,581.0)$ & $463.0(435.0,530.0)$ & 0.287 \\
\hline$(\mathrm{T} 1+\mathrm{T} 2+\mathrm{T} 3+\mathrm{T} 4 ;$ day $)$ & RA & $593.0(462.5,746.5)$ & $517.0(468.0,600.0)$ & 0.248 \\
\hline \multicolumn{2}{|c|}{ Follow-up (day) ${ }^{\dagger}$} & $\begin{array}{l}2095.0(1526.0 \\
2566.0)\end{array}$ & $743.0(567.0,807.0)$ & $<0.001$ * \\
\hline
\end{tabular}

* A p-value < 0.05 indicates a significant difference between the bovine and porcine bone groups. Data are presented as counts and percentages, except for continuous data $\left({ }^{\dagger}\right)$, which are expressed as the median and IQR.

$\neq$ There are two missing data points for the primary stability. RP: ridge preservation, RA: ridge augmentation.

\subsubsection{Maxillary Teeth}

For the maxillary implant sites, the bone density, T1, and follow-up time were significantly associated with the RA material $(p<0.05)$. Compared to the P-group cases, there was significantly more bone density, D4-D5, in the B-group implant sites ( $86.2 \%$ vs. $64.1 \%$, $p=0.014)$. For the implant sites with RA, the B group had a significantly longer time from extraction to RA date (T1; median of 84.0 vs. $40.5 \mathrm{~d}, p=0.03$ ). The B group had a longer follow-up time than the P group (median of 2095.0 vs. $743.0 \mathrm{~d}, p<0.001$ ). For the other implant site development variables (primary stability, BG, SL, post-operative infection, 
implant survival, T2, T3, T4, T2 + T3, T2 + T3 + T4, and T1 + T2 + T3 + T4), no significant associations with the $\mathrm{B}$ and $\mathrm{P}$ groups were observed (Table 3 ).

Table 4. Implant site development for bovine and porcine bone groups at mandible implant sites.

\begin{tabular}{|c|c|c|c|c|}
\hline & & $\begin{array}{l}\text { Bovine Bone, } \\
\text { BioOss }(n=45)\end{array}$ & $\begin{array}{c}\text { Porcine Bone, } \\
\text { MinerOss }(n=19)\end{array}$ & $p$-Value \\
\hline \multirow{3}{*}{ Primary stability } & $<20 \mathrm{~N}$ & $2(4.4 \%)$ & $4(21.1 \%)$ & \multirow{3}{*}{$0.036 *$} \\
\hline & $20-35 \mathrm{~N}$ & $9(20.0 \%)$ & $6(31.6 \%)$ & \\
\hline & $\geq 35 \mathrm{~N}$ & $34(75.6 \%)$ & $9(47.4 \%)$ & \\
\hline \multirow{2}{*}{ Bone density } & D1-D3 & $23(51.1 \%)$ & $4(21.1 \%)$ & \multirow{2}{*}{$0.030 *$} \\
\hline & D4 & $22(48.9 \%)$ & $15(78.9 \%)$ & \\
\hline \multirow[b]{2}{*}{ BG } & Yes & $27(60.0 \%)$ & $11(57.9 \%)$ & \multirow{2}{*}{$>0.999$} \\
\hline & No & $18(40.0 \%)$ & $8(42.1 \%)$ & \\
\hline \multirow{2}{*}{ Post-operative infection } & Yes & $4(8.9 \%)$ & $1(5.3 \%)$ & \multirow{2}{*}{$>0.999$} \\
\hline & No & $41(91.1 \%)$ & $18(94.7 \%)$ & \\
\hline \multirow{2}{*}{ Implant survival } & Early failure & $1(2.2 \%)$ & $0(0.0 \%)$ & \multirow{2}{*}{$>0.999$} \\
\hline & Survival & $44(97.8 \%)$ & $19(100.0 \%)$ & \\
\hline Extraction-bone grafting & $\mathrm{RP}$ & 0 & 0 & $>0.999$ \\
\hline$(\mathrm{T} 1, \text { day })^{\dagger}$ & RA & $41.0(20.0,117.0)$ & $42.0(37.0,55.0)$ & 0.771 \\
\hline \multicolumn{2}{|c|}{ 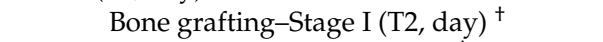 } & $110.0(89.0,133.0)$ & $140.0(121.0,151.0)$ & $0.003 *$ \\
\hline \multicolumn{2}{|c|}{ Stage I-Stage II (T3, day) ${ }^{\dagger}$} & $135.0(113.0,176.0)$ & $145.0(119.0,166.0)$ & 0.853 \\
\hline \multicolumn{2}{|c|}{ Stage II-prosthetic completion (T4, day) ${ }^{+}$} & $112.0(96.0,132.0)$ & $98.0(72.0,127.0)$ & 0.174 \\
\hline \multicolumn{2}{|c|}{ Bone grafting-Stage II $(\mathrm{T} 2+\mathrm{T} 3 \text {, day })^{\dagger}$} & $266.0(208.0,314.0)$ & $287.0(263.0,306.0)$ & 0.383 \\
\hline \multicolumn{2}{|c|}{ Bone grafting-completion $(\mathrm{T} 2+\mathrm{T} 3+\mathrm{T} 4 \text {, day })^{\dagger}$} & $390.0(336.0,417.0)$ & $378.0(326.0,415.0)$ & 0.356 \\
\hline Extraction-completion & $\mathrm{RP}$ & $385.0(322.0,417.0)$ & $407.0(354.0,415.0)$ & 0.524 \\
\hline$(\mathrm{T} 1+\mathrm{T} 2+\mathrm{T} 3+\mathrm{T} 4, \text { day })^{\dagger}$ & RA & $466.5(399.0,500.0)$ & $407.5(345.5,440.0)$ & 0.054 \\
\hline \multicolumn{2}{|c|}{ Follow-up (day) ${ }^{+}$} & $1970.0(1565.0,2241.0)$ & $555.0(352.0,773.0)$ & $<0.001$ * \\
\hline
\end{tabular}

* A $p$-value < 0.05 indicates a significant difference between the bovine and porcine bone groups. Data are presented as counts and percentages, except for continuous data $\left({ }^{\dagger}\right)$, which are expressed as the median and IQR. $\mathrm{RP}$ : ridge preservation, RA: ridge augmentation.

\subsubsection{Mandible Teeth}

For the implants at the mandible sites, significant associations between the primary stability, bone density, and T2 with the RA materials were observed. For the B group, 75.6\% of implant sites had primary stability $>35 \mathrm{~N}$; however, only $47.4 \%$ of the P group achieved this primary stability $(p=0.036)$. As regards implant sites with D4-D5, the percentages were $48.9 \%$ and $78.9 \%$ of the $\mathrm{B}$ and $\mathrm{P}$ groups, respectively $(p=0.030)$. The treatment time from RA to stage I (T2) was significantly shorter for the B group than P group (median of 110.0 vs. $140.0 \mathrm{~d}, p=0.003$ ). The $\mathrm{B}$ group had longer follow-up time than the P group (median of 1970.0 vs. 555.0 days, $p<0.001$ ). For the other implant site development variables (BG, SL, post-operative infection, implant survival, T1, T3, T4, T2 + T3, $\mathrm{T} 2+\mathrm{T} 3+\mathrm{T} 4$, and $\mathrm{T} 1+\mathrm{T} 2+\mathrm{T} 3+\mathrm{T} 4)$, no significant associations with the $\mathrm{B}$ and $\mathrm{P}$ groups were observed (Table 4$)$.

\section{Discussion}

A total of 116 subjects with 168 dental implants were included in this study. For the maxilla, the differences between the $\mathrm{B}$ and $\mathrm{P}$ groups were in age, coronal seal material, and bone density. For the mandible, significant differences between the two groups were found for the coronal seal material, ridge contouring time, primary stability, and bone density. However, no significant differences were found for the regrafting rate, post-operative infection rate, or implant survival rate. Implant sites using bovine bone as a bone grafting material were more likely to have better primary stability in the mandible only, but this significance was lost after adjustment for other factors.

Bio-Oss ${ }^{\circledR}$, physically and chemically like human bone, is the most well-known DBBM from spinal bone in dental application [6,17]. The porous particle size varies from 0.25 to $1.0 \mathrm{~mm}$ and the $\mathrm{Ca} / \mathrm{P}$ ratio is 1.92 [12]. However, to avoid potential bovine spongiform encephalopathy (BSE) transmission, other-origin xenografts have been developed [17]. Pigs and humans have physiological similarities, bone anatomy, and genotype [12,19]. The porcine-derived bone used in our study, MinerOss $\mathrm{XP}^{\circledR}$, is a highly porous inorganic mineral matrix with a particle size of $250-1000 \mu \mathrm{m}$ and a Ca/P ratio of $1.65-1.66$ [12,20]. In 
animal and human studies, $25-40 \%$ new bone formation has been observed for porcine bone after a 4-6-month healing period [9]. The macropores (diameter $>100 \mu \mathrm{m}$ ) and micropores (diameter $<10 \mu \mathrm{m}$ ) of both xenografts can promote angiogenesis and new bone ingrowth into the graft $[6,9,17]$. Further, both xenografts are osteoconductive, biocompatible, and resorbable in clinical application, including ridge and sinus augmentation $[6,8,9,17]$.

The clinical outcomes and histologic results achieved using porcine and bovine bone are comparable $[7,14,16,17]$. However, some studies have reported more new bone formation and less residual graft for porcine bone than bovine bone $[1,8,13]$. The difference between the bovine and porcine bone resorption rates depends on the pore size, pore morphology, pore percentage, connection between pores, pore connectivity, and granulometry $[1,8]$. When compared with naturally healed sockets, bovine bone decreased the relative proportion of vital bone, but, porcine bone enhanced new bone formation [1]. It is possible to shorten the treatment time between bone grafting and prosthetic completion in implant-site development using porcine bone. Bovine, porcine, and human trabecular bone have porosities of $70.5 \%, 78.4 \%$, and $79.3 \%$, respectively [6]. Furthermore, the $\mathrm{Ca} / \mathrm{P}$ ratio of porcine bone (1.65-1.66) is closer to the human $\mathrm{Ca} / \mathrm{P}$ ratio (1.68-1.71) than bovine bone (1.92) [12]. Porcine bone has also exhibited higher wettability (hydrophilic) than bovine bone, which could promote cell adhesion and proliferation [6,12].

No study has focused on the direct comparison of MinerOss and Bio-Oss for ridge preservation based on clinical and histologic analyses. However, an indirect comparison of MinerOss and Bio-Oss reveals no significant differences in the changes in ridge width (MinerOss: $-0.91 \mathrm{~mm}$ vs. Bio-Oss: $-0.38 \mathrm{~mm} /-4 \%$ ) or ridge height (MinerOss: $-0.37 \mathrm{~mm}$ vs. Bio-Oss: $1.56 \mathrm{~mm}$ ) [17,20]. Apart from ridge resorption reduction, the ideal graft material should promote bone formation to shorten treatment time [21]. Indirect comparison between MinerOss after four months of healing and Bio-Oss after 18-20 weeks of healing reveals differences in new bone formation (MinerOss: $57.43 \%$ vs. Bio-Oss: $36.21 \%$ ), the connective tissue portion (MinerOss: $22.99 \%$ vs. Bio-Oss: $43.32 \%$ ), and the residual bone graft (MinerOss:16.57\% vs. Bio-Oss: 20.47\%) [17,21]. Note that the average pore size $(474.26 \mu \mathrm{m})$, trabecular thickness $(121.76 \mu \mathrm{m})$, and pore connectivity (88-95\%) of MinerOss are similar to those of human bone [21].

In these applications, the bone density is affected by orthodontic treatment before dental implant placement; thus, orthodontic treatment was listed in the exclusion criteria of this study [22]. The results of this work indicate that the B group had lower bone density in the maxilla than the $\mathrm{P}$ group. This result is similar to the type III-IV bone densities previously reported for sinus augmentation cases [9]. The possible rationales of this difference are a far greater increase in bone density for the "bone graft combined with membrane" group than the "bone grafting only" group [13], and that porcine bone is closer to human trabecular bone in stiffness [11]. For similar particle size, the porcine xenograft was finer and more delicate than bovine bone. Thus, denser packing of porcine bone may occur under pressure during ridge recontouring, because of the "flaky" texture of this bone type [17]. However, in the maxilla, no significant difference in "primary stability" was found between the B and P groups in this work. The primary stability could be improved by under-preparation of the implant site. In contrast to the maxilla, in the mandible, significant differences were found between the two groups in terms of bone density and primary stability. However, the difference in osseointegration period in both jaws between the B and $\mathrm{P}$ groups was not affected by the differences in bone density and primary stability.

The regrafting rate of the $\mathrm{P}$ group during implant placement was compared to that of the B group. The results indicate that the developed ridge volumes of both groups may be similar; this finding agrees with the results of previous studies, which found that ridge preservation with porcine xenografts yields dimensional stability comparable to that of bovine xenografts $[17,23]$. However, in one of those previous works, additional grafting combined with implant placement was implemented because of thin buccal bone or lack of primary implant stability [17]. The intensive analysis performed in the present work 
revealed that the primary stability is not affected by the use of different xenografts in both jaws, after adjustment. However, better primary stability is associated with RP, because RA is usually applied to infected extraction sockets and poorly contained defects [24].

No significant differences in postsurgical infection symptoms and signs during the osteointegration phase were found between the $\mathrm{B}$ and $\mathrm{P}$ groups. Thus, the infection rate was not affected by the xenograft origin. The implant survival rate at sites developed using porcine bone were higher than those using bovine bone; however, the difference was not statistically significant. Post-infection signs were found in three cases of four early implant failure cases. Thus, the etiology of early implant failure may be associated with nongrafting factors such as infection [25]. Therefore, the other failure factors associated with xenografts for implant site development must be identified in future clinical trials. A significant difference in follow-up period after loading was found between the B and $P$ groups; thus, the late failure rate was not analyzed in this study. Note that only one late implant failure was recorded for group B after loading for 33 months. Overload is suspected to have induced this late implant failure.

This study was limited by its retrospective nature. First, fewer cases and shorter follow-up times were found for the P group than the B group. Second, a collagen plug was used as a coronal seal in most B-group cases, whereas a collagen membrane was used as a seal for the $\mathrm{P}$ group. The different seal materials may have affected the analysis. Third, the measurement of bone density was not used objective method and primary stability was not according to resonance frequency analysis. Finally, socket morphology data were missing; this morphology may have affected the remodeling after implant site development and, hence, the implant surgery outcome [24]. Therefore, bovine and porcine bone should be compared in clinical trials. Additionally, the effects of other factors on implant site development using different-origin xenografts should be investigated in the future.

\section{Conclusions}

The effects of implant site development using bovine- and porcine-origin xenografts are comparable in terms of implant-therapy clinical parameters, including the primary stability, regrafting rate, implant survival rate, and treatment time. This means that both xenografts resulted in predictable outcomes in terms of dental implant site development. Therefore, the choice of xenografts could be based on the patient's choice, with reasons such as religious considerations. However, these results should be viewed with caution because of the limitations of this retrospective study. In addition, it is necessary to study the relationship between other factors and xenografts in the future using a clinical trial.

Funding: This research received no external funding.

Institutional Review Board Statement: The protocol was approved by the Institutional Board of Chang-Gung Memorial Hospital (No. 202100702B0).

Informed Consent Statement: Patient consent was waived due to the retrospective nature of the study.

Data Availability Statement: Data sharing not applicable.

Conflicts of Interest: The authors declare no conflict of interest.

\section{References}

1. Corbella, S.; Taschieri, S.; Francetti, L.; Weinstein, R.; Del Fabbro, M. Histomorphometric Results After Postextraction Socket Healing with Different Biomaterials: A Systematic Review of the Literature and Meta-Analysis. Int. J. Oral Maxillofac. Implant. 2017, 32, 1001-1017. [CrossRef]

2. Messina, A.M.; Marini, L.; Oh, D.S.; Marini, E. A Step-by-Step Procedure for Bone Regeneration Using Calcium Phosphate Scaffolds: From Site Preparation to Graft Placement. J. Craniofac. Surg. 2019, 30, 149-153. [CrossRef]

3. Verket, A.; Lyngstadaas, S.P.; Tiainen, H.; Ronold, H.J.; Wohlfahrt, J.C. Impact of particulate deproteinized bovine bone mineral and porous titanium granules on early stability and osseointegration of dental implants in narrow marginal circumferential bone defects. Int. J. Oral Maxillofac. Surg. 2018, 47, 1086-1094. [CrossRef] 
4. Antonelli, A.; Bennardo, F.; Brancaccio, Y.; Barone, S.; Femiano, F.; Nucci, L.; Minervini, G.; Fortunato, L.; Attanasio, F.; Giudice, A. Can Bone Compaction Improve Primary Implant Stability? An In Vitro Comparative Study with Osseodensification Technique. Appl. Sci. 2020, 10, 8623. [CrossRef]

5. Testori, T.; Iezzi, G.; Manzon, L.; Fratto, G.; Piattelli, A.; Weinstein, R.L. High temperature-treated bovine porous hydroxyapatite in sinus augmentation procedures: A case report. Int. J. Periodontics Restor. Dent. 2012, 32, 295-301.

6. Lee, J.H.; Yi, G.S.; Lee, J.W.; Kim, D.J. Physicochemical characterization of porcine bone-derived grafting material and comparison with bovine xenografts for dental applications. J. Periodontal Implant Sci. 2017, 47, 388-401. [CrossRef]

7. Lee, J.S.; Shin, H.K.; Yun, J.H.; Cho, K.S. Randomized Clinical Trial of Maxillary Sinus Grafting using Deproteinized Porcine and Bovine Bone Mineral. Clin. Implant Dent. Relat. Res. 2017, 19, 140-150. [CrossRef] [PubMed]

8. Guarnieri, R.; DeVilliers, P.; Grande, M.; Stefanelli, L.V.; Carlo, S.D.; Pompa, G. Histologic evaluation of bone healing of adjacent alveolar sockets grafted with bovineand porcine-derived bone: A comparative case report in humans. Regen. Biomater. 2017, 4, $125-128$.

9. Iezzi, G.; Degidi, M.; Piattelli, A.; Mangano, C.; Scarano, A.; Shibli, J.A.; Perrotti, V. Comparative histological results of different biomaterials used in sinus augmentation procedures: A human study at 6 months. Clin. Oral Implant. Res. 2012, 23, 1369-1376. [CrossRef] [PubMed]

10. Figueiredo, M.; Henriques, J.; Martins, G.; Guerra, F.; Judas, F.; Figueiredo, H. Physicochemical characterization of biomaterials commonly used in dentistry as bone substitutes-comparison with human bone. J. Biomed. Mater. Res. B Appl. Biomater. 2010, 92, 409-419. [CrossRef] [PubMed]

11. Park, S.A.; Shin, J.W.; Yang, Y.I.; Kim, Y.K.; Park, K.D.; Lee, J.W.; Jo, I.H.; Kim, Y.J. In vitro study of osteogenic differentiation of bone marrow stromal cells on heat-treated porcine trabecular bone blocks. Biomaterials 2004, 25, 527-535. [CrossRef]

12. Bae, E.B.; Kim, H.J.; Ahn, J.J.; Bae, H.Y.; Kim, H.J.; Huh, J.B. Comparison of Bone Regeneration between Porcine-Derived and Bovine-Derived Xenografts in Rat Calvarial Defects: A Non-Inferiority Study. Materials 2019, 12, 3412. [CrossRef] [PubMed]

13. Chen, Y.W.; Chen, M.Y.; Hsieh, D.J.; Periasamy, S.; Yen, K.C.; Chuang, C.T.; Wang, H.C.; Tseng, F.W.; Kuo, J.C.; Chien, H.H. Evaluating the bone-regenerative role of the decellularized porcine bone xenograft in a canine extraction socket model. Clin. Exp. Dent. Res. 2020, 7, 409-418. [CrossRef] [PubMed]

14. Lee, J.S.; Cha, J.K.; Kim, C.S. Alveolar ridge regeneration of damaged extraction sockets using deproteinized porcine versus bovine bone minerals: A randomized clinical trial. Clin. Implant Dent. Relat. Res. 2018, 20, 729-737. [CrossRef] [PubMed]

15. Lim, H.C.; Jung, U.W.; You, H.; Lee, J.S. Randomized clinical trial of ridge preservation using porcine bone/cross-linked collagen vs. bovine bone/non-cross-linked collagen: Cone beam computed tomographic analysis. Clin. Oral Implant. Res. 2017, 28, 1492-1500. [CrossRef]

16. Koo, T.H.; Song, Y.W.; Cha, J.K.; Jung, U.W.; Kim, C.S.; Lee, J.S. Histologic analysis following grafting of damaged extraction sockets using deproteinized bovine or porcine bone mineral: A randomized clinical trial. Clin. Oral Implant. Res. 2020, 31, 93-102. [CrossRef]

17. Lai, V.J.; Michalek, J.E.; Liu, Q.; Mealey, B.L. Ridge preservation following tooth extraction using bovine xenograft compared with porcine xenograft: A randomized controlled clinical trial. J. Periodontol. 2020, 91, 361-368. [CrossRef]

18. Misch, C.E. Bone character: Second vital implant criterion. Dent. Today 1988, 7, 39-40.

19. Mardas, N.; Dereka, X.; Donos, N.; Dard, M. Experimental model for bone regeneration in oral and cranio-maxillo-facial surgery. J. Invest. Surg. 2014, 27, 32-49. [CrossRef]

20. Guarnieri, R.; Stefanelli, L.; De Angelis, F.; Mencio, F.; Pompa, G.; Di Carlo, S. Extraction Socket Preservation Using PorcineDerived Collagen Membrane Alone or Associated with Porcine-Derived Bone. Clinical Results of Randomized Controlled Study. J. Oral Maxillofac. Res. 2017, 8, e5. [CrossRef]

21. Guarnieri, R.; Testarelli, L.; Stefanelli, L.; De Angelis, F.; Mencio, F.; Pompa, G.; Di Carlo, S. Bone Healing in Extraction Sockets Covered with Collagen Membrane Alone or Associated with Porcine-Derived Bone Graft: A Comparative Histological and Histomorphometric Analysis. J. Oral Maxillofac. Res. 2017, 8, e4. [CrossRef] [PubMed]

22. Chang, L.C.; Tsai, I.M. Comparison of Early Implant Failure Rates between Subjects with and without Orthodontic Treatment Before Dental Implantation. J. Oral Implantol. 2019, 45, 29-34. [CrossRef] [PubMed]

23. Giuliani, A.; Iezzi, G.; Mazzoni, S.; Piattelli, A.; Perrotti, V.; Barone, A. Regenerative properties of collagenated porcine bone grafts in human maxilla: Demonstrative study of the kinetics by synchrotron radiation microtomography and light microscopy. Clin. Oral Investig. 2018, 22, 505-513. [CrossRef]

24. Chang, L.-C.; Cheng, Y.-M. The Effect of Different Socket Types on Implant Therapy While Using Flapless Ridge Preservation. Appl. Sci. 2021, 11, 970. [CrossRef]

25. Chang, L.C. Risk factors associated with early failure of maxillary versus mandibular implants: A retrospective study. Int. J. Oral Implantol. 2020, 13, 55-63. 